\title{
Critical Service-Learning as a Vehicle for Change in Higher Education Courses
}

\author{
Kiesha Warren-Gordon \& Cristina Santamaría Graff
}

Our story begins with us, two female faculty members of Color, meeting through a faculty fellowship program focused on service-learning. Through this program, we soon discovered that the work in which we were engaged could be categorized as Critical ServiceLearning (CSL), which is similar to, but distinctive from service-learning. Service-learning is a "course-based, credit bearing educational experience" (Bringle \& Clayton, 2012, p. 105) through which students in higher education develop a greater sense of civic responsibility while participating in acts that are mutually identified and organized to benefit the community.

CSL is a response to traditional service-learning. Though structured similarly, it explicitly places social justice as central to the interactions between students and community members (Butin, 2015; Mitchell, 2008, 2014). Further, practitioners of CSL deliberately integrate pedagogy centered on social justice frameworks used to raise critical consciousness in order to take purposeful action (praxis) against structural injustice or violence (Mitchell \& Rost-Banik, 2016). This pedagogy is not discipline-specific. It can be developed to enhance ways in which students recognize their own implicit biases as they make sense of their discipline in relation to the individuals and community members they impact through their work.

As faculty of Color who work primarily with undergraduate students who are white, middle-class, and monolingual English-speaking, we are particularly interested in troubling

This is the author's manuscript of the article published in final edited form as: 
traditional notions of service-learning that do not explicitly address the power differentials experienced when white students enter disenfranchised communities of historically minoritized populations. Our narrative centers on decisions we made individually and jointly in constructing CSL-based projects within our respective disciplines. We hope that our discussion will illuminate ways to confront white hegemony directly while describing the conscientious deliberations needed to ensure that community stakeholders are respected, cared for, and provided opportunities to critique and inform serving-learning projects.

\section{Our Positionalities, Our Life's Work}

As two female professors of Color, our work is very personal through it is situated within an academic, professional context. Warren-Gordon, an African American mother of three children, is also a professor of Criminal Justice and Criminology. Though trained as a social scientist, she is currently immersed in community-based work. Her passion for creating a safe world in which her three young children can grow up without being threatened, hurt, or killed, has led her to create courses in which predominantly white future law enforcement agents work and interact with Black community leaders.

Santamaría Graff, a self-identified biracial Mexicana and a professor in a special education teacher preparation program, is committed to the spirit of the current special education law, which dictates that parents are equal stakeholders in the educational decisionmaking that impacts their children. Taking this statement at face value, Santamaría Graff works 
with parents of children with disabilities who co-teach the special education family course she teaches.

The purpose of both of our projects - intentionally created to promote social justice - is to change negative mindsets or belief systems among our white students (and other students) about specific individuals and/or communities of Color. In line with this purpose, we believe transformation can only take place when individuals embrace all knowledges, embody the spirit of openness and learning, and enact mindful, conscientious acts that benefit all members within a community.

\section{Warren-Gordon: Critiquing Notions of Crime Among Future Law Enforcement Agents}

Warren-Gordon was instrumental in developing a new Criminal Justice and Criminology course at her university. This course was intended to help students to understand the many ways in which social service agencies interacted with those who were supervised by the justice system. These agencies provided various forms of support to individuals who were at risk of taking part in crime.

To understand the ways in which crime had been associated with historically minoritized populations, Warren Gordon's course emphasized the importance of reconceptualizing crime as a concept and practice. She focused on changing students' negative dispositional attitudes toward minoritized groups in her local area, specifically African Americans, who resided near her university. Aware that this population was disproportionately represented in the local 
criminal justice system in arrests and incarcerations, she wanted her students to understand the role structural racism and inequitable local policies played in criminalizing these residents.

During the summer of 2017, Warren-Gordon worked with community leaders to develop a plan for the course that would meet a 'community need' and address learning goals of critical service-learning and course subject matter. These learning goals were co-constructed with Santamaría Graff and were centered around social justice acts that were inclusive of unpacking racial biases and recognizing power differentials based on one's positionality or status.

Warren-Gordon partnered with the local community council to develop a "hands-on" program through which her students could gain a stronger understanding of community members' concerns, social service agencies' resources, and the local criminal justice system. The local council provided feedback regarding assigned readings, reflection assignments, and logistical arrangements of dates and times as to when the students would be learning from and working with community members. In essence, the Black leaders of the community were coeducators and informed course pedagogy.

During the Fall 2017 semester, the 20 students enrolled in the class took a bus tour of the community led by the Black community leaders. These leaders educated the students on the sociohistorical context of racism and violence against the Black community as well as the 
ways in which city planning had minimized the community's ability to access healthy food, a phenomenon often referred to as a "food desert."

This guided tour laid the foundation for a survey and interview questions developed by students for the community members around issues of safety within the community. Students led focus groups based on community members' recommendations then transcribed and analyzed the focus groups and interviews for themes. Sixty-five community members completed the surveys.

Students' findings suggested that the community safety concerns were centered on a lack of street lighting, minimal sidewalks for children to play and walk, and an unsettling number of roaming dogs in the neighborhood. From the survey data collected, students decided to research state statutes centered on dog control. Using information gathered, students created a brochure for the community providing specific guidelines of what to do if a stray or roaming dog was found, how to determine mistreatment, and how to assist the owner by providing helpful support. These brochures were passed out to apartment complexes and neighborhoods in the community. Community members had and continue to have monthly meetings to discuss these state statues in a proactive manner to promote educational awareness around the issue of leash-free, roaming dogs. With this growing awareness of how to approach this community issue, more community members have been taking greater responsibility to inform dog owners ways to care properly for their pets and to ensure community safety. Students in Warren-Gordon's course concluded that community members could benefit greatly by becoming more explicitly aware of specific community activities and 
events focused on community safety. These findings shaped the Spring 2018 follow-up course in which students worked to develop solutions to the problems the Fall 2017 students identified.

\section{Santamaría Graff: Affirming the Role of Parents as Experts of their Children}

In fall 2016, Santamaría Graff implemented a "Family as Faculty" model in a pre-service special education course targeting undergraduate, pre-service special education teachers. A "Family as Faculty" approach, as reconceptualized from educational literature, is one in which families are positioned as experts and leaders in university courses and situated as coinstructors/educators. With assistance from a statewide parent-to-parent organization, Santamaría Graff recruited eight parent participants ( 7 female, 1 male; including 2 Latina mothers and 1 African American mother) who co-planned course content and led class discussions on special education topics.

These topics were presented through an insider lens to impress upon the pre-service teacher/student-participants (22 total) the importance of family member expertise in the educational decision-making processes impacting students with disabilities. Data gathered from the mixed-methods study associated with this project demonstrated that pre-service teachers increased their understanding of culturally responsive practices in relation to parents whose first language was not English. Further, pre-service teachers' understandings of parent participation, particularly parents from historically minoritized backgrounds, expanded as many realized the myriad of ways parents are actively involved in their children's education. Many 
understood parents' involvement not merely as school-based "acts" of participation but rather as moment-to-moment care and nurturing of the child's overall well-being.

In the second iteration of the "Family as Faculty" project, which occurred in Fall 2018, parents (13 total) were the co-instructors of a special education graduate course focused on families. They not only co-planned and taught the course but also worked with the graduate students (13 total) and a non-profit organization that supports parents/families with children with Down Syndrome to organize a conference on inclusion for parents/families, individuals with disabilities, educators, and other community stakeholders. Purposeful collaboration between parents and students during conference-planning sessions was the core of this service-learning project.

This collaboration was, at times, challenging for students particularly when parents posed questions that centered around the intersections of race, class, and ability to help students understand the complexities of inclusion. For example, during a parent-led class, one parent from Nicaragua presented students with a case study about her Spanish-speaking child with Down Syndrome. She did not tell the students the case study was about her child but rather posed ethical questions about ways in which her child had been discriminated against for having a cognitive disability and being Spanish-speaking.

Students were uncomfortable reading about the child's treatment in school by a particular teacher and did not understand how the child could be so marginalized within a 'public' system. When the parent revealed that the case study centered on her own 
experiences with her child, the students were visibly shaken. They responded with many explicit questions for the parent about how they could have made the situation better had they been the teacher.

Through active listening they learned specific strategies they had never considered before that could have benefited this Spanish-speaking child with Down Syndrome. The parent shared strategies as simple as making sure the child was in a familiar and comfortable environment before expecting her to answer questions and behave a certain way. These strategies helped students question their own biases and assumptions stemming from dominant ideologies as they began to think critically about the ways they could perpetuate or disrupt oppressive teaching practices.

Data collected through Family as Faculty (FAF) projects embedded in special education courses indicated that students (undergraduate and graduate) held assumptions that parents, particularly Spanish-speaking parents, were not interested in their children's education. One major outcome of FAF projects was that many students turned their critical lens inward. They realized that to have parents and families engaged more in the classroom meant that they, future educators, had to make concerted efforts to create welcoming environments for families in their classrooms or schools. Some students began learning Spanish phrases so that they could greet and speak with their students' family members. Others started to conceptualize ways to transform their classroom or school spaces to highlight their students' families' strengths (e.g., photos of their parents working, gardening, baking, painting, singing, etc.). 
Reflecting upon their own preconceived assumptions of parent involvement provided a critical beginning for thinking about and applying culturally responsive practices to their own pedagogical understandings. Through their work with parents and family members of children with disabilities university students learned the importance of seeing them as equal knowledgemakers in the educational decisions impacting their children.

\section{Conclusion}

Integrating CSL in our courses meant intentionally structuring activities to challenge students' biases and preconceived notions about people of Color and, more broadly, those who are different from a dominant white, Eurocentric norm. Warren-Gordon asked her students to describe how their positionality as students with privilege impacted their preconceptions of working with Black community members around issues of crime and safety. Students were given opportunities to be uncomfortable in communities in which they were the 'minority' and were unfamiliar with their surroundings. They were encouraged to think about the root of their fears and to unpack, in frank class discussions, their unease and discomfort.

They were also prompted to think about how Black communities were both different from and similar to their own. By directly interacting with and learning from Black leaders, students began to question their prejudices and racist thinking by considering how predominant white hegemonic systems paint Black people as criminals and individuals to be feared. 
Santamaría Graff, in conjunction with parents of children with disabilities, coconstructed curriculum through readings and activities that focused on parents' insider expertise of their children. By learning from parents, students had the opportunity to experience them as equal stakeholders in educational processes centered on the child. Students' traditional understandings of the teacher owning knowledge and knowing what is best for the child was disrupted through critical understandings through the Family as Faculty projects. Findings collected through several data points demonstrated that students actively challenged their own assumptions and began seeing parents as important educational leaders.

As CSL practitioners, every moment we engage students in community-based or driven work is a teachable one. Teachable moments in the communities to which we each are committed are meaningful understandings emerging from "hands-on," authentic interactions between students and community members. Profound realization and internal change occur when students, particularly white students, connect community members' lived experiences of marginalization to course materials about white hegemonic oppression on a systemic level. This depth of understanding is what we aim for as we dedicate time and energy to long-term sustainable projects that will, over time, dismantle oppressive practices and promote transformative change that will directly benefit the individuals in the communities with whom we collaborate. 


\section{References}

Bringle, R. G., \& Clayton, P. H. (2012). Civic education through service-learning: What, how, and why? In L. Mcllrath, A. Lyons, \& R. Munck (Eds.), Higher education and civic engagement: Comparative perspectives (pp. $101-124)$. New York: Palgrave.

Butin, D. (2015). Dreaming of justice: Critical Service-learning and the need to wake up. Theory Into Practice, 54, 5 - 10.

Mitchell, T. D. (2008). Traditional vs. Critical Service-Learning: Engaging the literature to differentiate two models. Michigan Journal of Community Service Learning, 50 - 65.

Mitchell, T. D. (2014). How service-learning enacts social justice sensemaking. Journal of Critical Thought and Praxis, 2(2), Article 6, 1- 26.

Mitchell, T., \& Rost-Banik, C. (2016). Critical theories and student civic outcomes. In J. Hatcher, R. G. Bringle, and T. W. Hahn (Eds.), Research on Student Civic Outcomes in Service Learning: Conceptual Frameworks and Methods (pp. 177 - 197). Sterling, VA: Stylus Publishing, LLC. 